(C. gracilis, Fories), and the limb bones of three species, belonging to a new genus Palcocasuarius (Forbes), of the Dinornithide.

Dr. D. Sharp, F.R.S. exhibited some ants and their sound producing organs. The sound-producing organs of ants consist of very fine parallel lines engraved on a portion of the outer surface of the chitinous skeleton and of a scraper or very fine edge. Great delicacy of movement may be given to the latter instrument by means of a ball-and-socket joint.

Sections showing the microscopic structure of certain fossil cryptogamic plants from the coal-measures, exhibited by Prof. W. C. Williamson, F.R.S., and Dr. D. H. Scott; white corpuscles of the blood and lymph under the microscope, exhibited by Mr. W. B. Hardy and Dr. A. A. Kanthack; maps and photographs illustrating the Sandgate Landslip, exhibited by Mr. W. Topley, F.R.S., and Mr. R. Kerr, F.G.S.

Mr. Edward Matthey F.C.S. exhibited form in which antimony separates from bismuth at a temperature of $35^{\circ} \mathrm{C}$. The specimens are those of the film as removed from the surface of the melted antimonial bismuth. They consist of antimony oxide, containing about ten per cent. of bismuth.

Two compact voltaic batteries of zinc and platinum, were shown by Dr. G. Gore, F.R.S.

Major P. A. MacMahon, F.R.S., exhibited peramutational tesselations. A new method of obtaining designs for tesselated pavements, based upon the property possessed by the twenty four different isosceles right-angled triangles derived by permuting four designs in all possible ways upon the sides.

Mr. E. Wethered exhibited photo-micrographic lantern slides, illustrating the micro-organisms in limestone rocks. The slides especially illustrate the remarkable structure known as Girvanella.

Lord Armstrons, C. B., F.R.S., exhibited experiments to show the nature of the electric discharge in air and water. The experiments will all be exhibited in action on the screen of the electric lantern, and will include the transfer of a cotton string from one vessel to another by means of a current of water flowing within another under the influence of electricity. Various dust figures will also be formed and similarly shown, displaying the nature and effects of the electric discharge in air.

Preparations and photographs demonstrating the action of solar and electric light on the spores of bacteria and fungi, exhibited by Prof. 11. Marshall Ward, F.R.S.

\section{THE INTERDEPENDENCE OF ABSTRACT SCIENCE AND ENGINEERING.}

N Thursday evening, May 4, the first "James Forrest" Lecture was delivered at the Institution of Civil Engineers, by Dr. William Anderson, F.R.S. The subject was "the interdependence of abstract science and engineering." After briefly explaining the origin of the lecture, Dr. Anderson proceeded :-The theme which has been prescribed is "The Interdependence of Abstract Science and Engineering," and I imagine that the subject has been chosen because of an uneasy feeling, which possesses many thoughtful men, that this country is not keeping pace with its neighbours in engineering progress, and that we shall, in the future, have to pay more attention to abstract science and its application to practice, than we have been, so far, in the habit of doing.

With rare exceptions, in this country, has there been even a slender amount of theoretical knowledge imparted to various grades of employment; it is only during the last few years that Science Colleges and technical education in schools and People's Palaces, are beginning to bring our operatives up to the level of our foreign friends, but, unfortunately, too late to retain that preeminence which we at one time could claim, and, I fear, placed too much confidence in ; and moreover, a new danger has arisen in the circumstance that popular scientific education has taken a one-sided direction, that of mechanical and technical knowledge alone, so that, though the operative approaches his work with increased intelligence, he remains unfit to reason out the great economic problems on which his own welfare and that of the nation depend.

It is a matter of extreme surprise to me that so little attention is paid to the science of Political Economy, that not only the mass of the people, in whose hands the voting power now lies, but even, in a great measure, the representatives whom they elect, have no systematic training in, and are grossly ignorant of, the principles which lie at the root of national prosperity. The further misfortune follows that politicians of the highest position do not scruple to trade on this ignorance, or pursue a course which, in its consequences, is as bad-being ignorant themselves they strive to lead the ignorant, and set the operative against his employer and against society in general. The cheapness of newspapers, their wide diffusion, and their blind, not to say reckless advocacy of popular fallacies acting on the ignorance, prejudices, and discomfort, if not suffering, of the operative classes, are giving enormous power to trade organisations, whose avowed object it is to improve the earnings and social standing of the operative at the expense of, or at any rate without regard to, the interests of every other class in the community, and this is to be accomplished not by encouraging education, not by advocating thrift and temperance, not by urging the workman to improve his mechanical dexterity, the thoroughnesss of his work and the amount which he produces, but by holding out visions of shortened hours of labour, by compelling a minimum of pay which will enable him to live in comfort, of systematically restricting the amount of work done by each individual, even in the shortened day, all under the fatal illusion that by such means a greater number of men will find more remunerative employment.

The employer is usually credited, by the trade leaders, with accumulating wealth without effort, risk, or anxiety, by the slavish labour of his operatives, while the proofs to the contrary, so easily to be obtained in the slender dividends declared by most industrial enterprises, and in the records of the Bankruptcy Courts, are steadily kept out of view.

There would be no fault to find with the new class of professional agitators, who live by the discontent which they foment, were they, and the Unions which they manipulate, to contribute in the smallest degree to the obtaining of that work and of those orders, in the execution of which the wage-earning portion of the community have their being. This, the most difficult part of every commercial enterprise, is left to the much-abused capitalist, so that the absurd and impossible system is fast asserting itself, that professional skill, mercantile ability, and capital, shall obtain the work, and run all the risk of design, execution, and tinancial security; but that work shall be carried out according to rules which self constituted and perfectly irresponsible bodies choose to impose. The smallest acquaintance with the principles of political economy would demonstrate that such methods must end in ruin, that they are utterly incompatible with our policy of Free Trade-a system which is perfectly reasonable and proper if thoroughly carried out, and which certainly never contemplated the protection of one particular class, and that, not by edict of the State, but at the bidding of self-constituted tribunals whose claims amount to this:-that there shall be free trade in all products which the operatives require to buy, but the strictest protection as to all that they have to sell, namely their labour, and whose ultimate methods are violence, and the coercion of all who differ from views which many intelligent but timid workmen know to be at variance with the true interests of their class.

Under all this lies the socialistic idea of equality in the condition of every member of the community, an idea which political economy demonstrates to be utterly Utopian and impossible. Since the creation of mankind the differences in social position and in material comfort which follow naturally from the endless variations of mental and bodily powers in men, have existed, and, in spite of many abortive attempts, more or less violent, to establish equality, will exist for ever; for it seems to me that the doctrine of Carnot with respect to heat-engines applies by analogy to the question of national prosperity. To obtain mechanical power from a source of heat there must be a fall of temperature, and the greater that fall is the more efficient will the engine be-a dead level of temperature simply means extinction of energy and of life. To ensure active trade and prosperous manufactures there must be a fall of money or of its equivalent from the wealthy to the comparatively poor, the one class is absolutely essential to the other; the prosperity of the community is bound up in the existence of these differences, and a dead level of wealth would be a dead level of poverty, which would end, as a state of uniform temperature must end, in absolute stagnation and death.

However much we may regret the inequality which exists in the distribution of wealth and comfort, it is just as much a law of nature as the unequal distribution of warmth, of sunshine, or of rain, and seems to me to follow naturally and inevitably

NO. I 229 , VOL. 48 ] 
from the endless variations in the physical, moral, and mental powers of human beings, and therefore to be as unalterable at the bidding of man as these attributes are. It only remains for us to recognise the fact, to make the best of it, and to avoid the gross wickedness of attempting to delude the poorer and more ignorant members of the community by incessant representations that it is the greed and selfishness of the wealthy which keep them low.

If the so-called "working man" be the embodiment of all that is needed for the industrial prosperity of a country, and if the possession of capital and the far wider consequence, the existence of credit, be a crime, why does he not arise in his strength and exhibit the faculties of combination which are so well illustrated in the trades unions, and establish engineering works and manufactories, or undertake engineering enterprises from which he will be able himself to reap the golden harvest which the capitalist and the shareholder are supposed to gather, and who thereby excite his envy and arouse his hatred.

In deference, I presume, to the immense numerical importance of the operative classes, politicians are vieing with each other in supporting the impossible claims put forth-claims which, if conceded, will only precipitate the ruin of the class they profess to benefit, and which already is the form of what may be termed benevolent legislation in favour of the operative, is heaping up elements of cost which our productive energy is unable to bear. The absurd cry that manual labour is the sole source of wealth has been well combated by that acute reasoner, Mr. Macfarlane Gray, who, in a recent discussion on the labour question, happily compared the body politic to a tree. The popular beliet is that plants are nourished through their roots, which for that reason are believed to be the all-important parts, while the leaves are mere ornaments, enjoying the upper air and sunshine and profiting by the work done underground. But a juster knowledge, one of the fruits of abstract investigation, tells us that the roots are mainly useful in holding the tree erect, and have comparatively little to do with providing the materials for building up its structure. It is the leaves which form the great laboratory in which the main components of the plant are ex tracted from the region where superficial observers would least expect to find them-namely, from the atmosphere. He compares the roots to the operatives' part of the community; the trunk and leaves to the monetary, the scientific and the commercial part which drew from far and wide that which is necessary to keep the growth advancing and maintain it in health. The roots may just as well claim to be the sole sources of life in the tree as the operatives may claim to be the only producers of wealth, and conversely the leaves could, with as much reason, consider themselves as the only essential portion of the plant as the merchant or the capitalist claim to be independent of the operatives. Each grade in the body politic is essential to the other ; it is an axiom that there can be no degrees of comparison between essential parts ; and those who, from ignorance or from interested motives, persistently preach the doctrine of the superior importance of the "masses" over the "classes" are inficting a deep injury on the prosperity of the country, and especially on those whom they so grossly flatter.

Nothing, save bitter experience, will alter the course of events. It seems to be the fate of peoples to attack social problems from the wrong end, to solve them by the painful and dilatory process of trial and error, rather than by means of investigation based on first principles. And this method is commonly applied to engineering problems also. Random trials, as a rule, are the methods by which great results have been achieved, while the application of the scientific principles involved have been left to other heads long after the results sought have been at. tained at much needless cost, and by much unnecessary expenditure of labour and of time.

It is not often that a genius of the order of James Watt rises in the mechanical world. Up to his time the "fire-engine," as it was most properly called, was being slowly developed without any exact knowledge of the properties of the agent by means of which the heat generated by the combustion of fuel was converted into work, and this in spite of the circumstance that such a master mind as that of Smeaton had been directed to perfecting the new method of utilising the potential energy of fuel, and of applying it to engines of large power, and on an extensive industrial scale.

The lucky chance which presented itself of having to put in order a working model of a Newcomen engine illustrates in an interesting manner how, in pursuance of his business, he quickly NO. I 229 , vOL. 48 ] executed the necessary repairs and alterations, and afterwards, at greater leisure, attacked the problem which the failure of the model presented, from the theoretical side, but soon found that the then state of knowledge did not afford the means of explaining the failure, and compelled him to set about the determination of such elementary data as the specific volume of steam, the latent heat of evaporation, and the law of tension of steam under varying temperatures. In the astonishingly short period of two years, and with the rudest and cheapest apparatus, he had furnished himself with the abstract knowledge required for explaining in a definite manner the action of the steam engine, and he had no difficulty, as soon as his theoretical ground was sure, in determining what mechanical arrangements were necessary to realise the conditions imposed by science. From investigations apparently of an abstract or non-practical character, sprung at once the separate condenser, the closed cylinder and the equilibrium working of a single-acting engine, the steam jacket, the air-pump, the theory of expansive working, the function of the momentum of the moving parts, and the exact calculations based on first principles by means of which the proportions of engines could be fixed, and the quantities of steam, water, and of fuel calculated. Watt, of course, was a born mechanic, as well as a seeker after physical knowledge. The u orkshop in his house near Birmingham, happily preserved to this day as he left it, shows that his mind was ever bent on mechanical contrivances which his own hands were skilful enough to carry out ; his valvegear, the stuffing box, the parallel motion, the governor, are all instances of that happy blending of mechanical skill and of scientific research which must ever mark the qualifications of a great mechanical engineer.

A contrast to Watt's achievements is the singular history of the development of iron and steel bridge building, which necessarily followed the introduction of railways. Watt felt the want of first principles by which to shape his actions, and set about discovering them ; but the principles which underlie the determination of stresses in braced structures, such as roofs and frameworks of various kinds, as well as those in solid bars subjected to the action of transverse forces, have long been known ; and early in this century Navier made them the subjects of lectures at the École des Ponts et Chaussées, yet engineers in this country seem to have been but dimly aware of them, or, at any rate, to have made little use of the knowledge which was at their disposal. It is difficult, from the published histories of such enterprises as the Conway and Britannia bridges, to arrive at any conclusion as to the extent of knowledge, or rather ignorance, which existed among engineers before these works were commenced. It is sufficiently evident, however, from the long series of purely tentative experiments by which the proportions of the Conway and Britannia bridges were determined, as well as from the singular vagaries to be noticed in the smaller bridges of that day, that only the haziest ideas of the disposition of stresses, and of the functions of the component members of girders existed.

In the experimental investigations of the time, the function of the web or vertical member of a girder was completely ignored, for it was looked upon merely as the means of keeping the top and bottom flanges in their relative positions, while the essential difference in effect of a uniformly distributed load, or of a rolling load, as compared with a load concentrated at the centre, on the vertical member of a girder, and even on the flanges, appears to have been overlooked till made evident by the results of experiment. Yet the principle that a force cannot change its direction unless combined with another force acting in a direction inclined to it, was perfectly well known, and should have led to the discovery that it is only by diagonal stresses in the vertical members that the load resting on a beam can be transmitted to the abutments; that the stresses due to loads concentrated at the centre were very different to those arising, both in the vertical web and in the flanges, from the action due to a load distributed in a given manner along the top or the bottom flanges, and that a rolling load would produce effects peculiar to itself.

The girder with diagonally braced webs, or the lattice girder, as it is commonly called, appears to have had its origin in Ireland; at any rate it was in that country that it received its earliest and chief development; and in the hands of Wild, Barton, Bow, and Stoney, the true principles began to assert themselves, and Mr. Barton's Cusher River bridge, of 70 feet span, on the Great Northern of Ireland Railway, was probably the first example of a lattice girder in which the cross-sections of the members of the webs as well as those of the flanges were 
correctly proportioned to the stresses imposed by a rolling load. This comparatively small bridge was followed by the Boyne viaduct at Drogheda, which must ever rank as a signal illustration of the successful application of abstract principles to a great work by men who were capable, not only of appreciating them, but of following their guidance in a practical manner.

The wrought-iron portion of the viaduct consists of three spans, the main girders of which are continuous; and the points of contrary flexure in the middle, and larger span, were determined by direct calculation, the correctness of which was demonstrated in the actual structure by setting free the plates of the flanges at the points indicated, and by observing the opening and closing of the plates so disunited when the land ends of the girders forming the side spans were raised or lowered.

Mr. Wild appears to have been the first to demonstrate correctly the distribution of stresses under any disposition of load in the Warren girder, a form of beam in which the web is composed of a single system of diagonal bracing inclined at an angle of about $60^{\circ}$. In the museum of Trinity College, Dublin, there has existed since, I believe 1854 , a model of a Warren girder, 12 feet 6 inches long and 12 inches deep, in which the tension members both of the flanges and diagonal bracing are so arranged and articulated that any one section can be taken out and a spring balance inserted, by means of which it can be demonstrated that the stresses calculated for any disposition of load do actually arise.

The history of scientific research teems with instances of discoveries which at first seem to have had no practical value, but which nevertheless have ultimately proved to be of the utmost importance to the engineer. For example, the changes of temperature which occur in many chemical reactions were merely noted at first as interesting accompaniments to such reactions ; but, by degrees, it was perceived that the amount of heat evolved or absorbed in each cliange was a constant and definite quantity, capable of exact measurement, and in process of time the thermal values which characterised a vast number of chemical changes were determined, and are now considered of cardinal importance in many industrial operations, and constitute the science of thermo-chemistry, and render it possible to judge of the efficiency of a boiler, for instance, when the rate of fuel combustion and that at which the water was heated or evaporated were known, by calculating the proportion which the heat imparted to the water bore to that produced by the combustion of any fuel of which the chemical composition had been ascertained, and from which the heat capable of being developed could be calculated by general rules.

One practical effect of the exact knowledge which every com. petent engineer now possesses on this subject, or can easily obtain, is that inventors have ceased to squander their time and their means in seeking for impossible high boiler duty, and the public is no more entreated to try contrivances which are to save at least 50 per cent. of the fuel they use, because inventors know that the testing of boilers is now usually carried out by experienced and educated men, who, by very simple and inexpensive trials, obtain the data by means of which they can calculate with certainty how much scope for improvement actually exists

Still more remarkable perhaps is the application of thermochemistry to the complicated reactions in the blast and regenerative furnace, and the valuable conclusions arrived at in conse. quence by such thorough and patient investigators as Sir Isaac Lowthian Bell, Sir William Siemens, Charles Cochrane, and others who have succeeded in equating the heat-units resulting from the oxidation of fuel to the ultimate thermal results of the decomposition of the ore and fluxes, showing thereby the limits of economy which the ironmaster may hope to reach, and the proportions of the furnaces in which his expectations may be realised.

No less valuable have been the fruits yielded by the discovery of the great law of the Conservation of Energy, and by the recognition of the fact that, though energy cannot be destroyed, it may be made to assume various forms, and may be reridered either dormant or active. The sun's rays, aeons of ages ago, during the dense vegetation which characterised the period of the coal measures, expended their energy in tearing asunder the carbon and oxygen of the carbonic acid distributed through the atmosphere, and in storing the carbon, thus endowed with potential energy, in the deposits whence we now derive our coal supplies. By suitable arrangements this dormant energy is quickened into that quality of motion which we recognise as heat, and which, setting into sympalhetic vibrations the material of the furnace-plates and smoke-flues of boilers, operates on the surrounding water, the molecules of which, under this influence, assume the more extended movements of the highly elastic substance which we know as steam. The products of combustion, on the one hand, are restored to the atmosphere, their remaining store of heat is slowly dissipated, while the carbonic acid gas produced in combus. tion is again ready to present itself, in the green leaves of plants, to the decomposing action of the sun, auil by that means the carbon and the oxygen become once more sources of heat. The steam produced, on the other hand, communicates its molecular motion to external bodies in various heating operations, in the visible motion and force of the steam-engine or into the slower dissipation through space or over the earth, whereby it is again condensed to water and returned to its normal condition, while the energy, for the exhibition of which, Carnot has taught us, steam was the mere agent, becomes transformed into masses of water lifted, into air compressed, into electrical currents generated, into mechanical work done, or into the heat developed by friction; but the general tendency is towards dissipation under the form of heat into space, the waste being made good by the stores of heat poured on to our planetary system by the huge and mysterious body which is its centre.

But modern investigators, and, most of all, engineers, are not content with vague statements such as $I$ have just made; they hold with the motto of the ancient Society of Civil Engineers, "Omnia in numero pondere et mensura," and they are therefore greatly indebted to Rumford, Carnot, Davy, Mayer, and Joule, who not only showed that heat was a "mode of motion," but determined by tedious and delicate experiments its mechanical equivalent.

And what is now the result?

When examining heat-engines or other applications of heat in the arts, the engineer collects the apparently aimless work of half a century, and of many minds, and finds himself able to construct a balance sheet by which he can show on the Dr. side, to a fraction, the quantity of heat he has received, and on the $\mathrm{Cr}$, page, with astonishing precision, the manner in which that heat has been expended. This method of treatment is not only lucid, but it is self-checking, and it points out exactly how much heat has been uselessly dissipated, and consequently in what direction improvements may be made, and it indicated further, the limits within which it is alone possible to make advances in economy.

These general principles apply even to the conversion of heat into the work done in the bore of a gun. The enormous pressures which require to be developed in order to impress high velocity on the projectile in the necessarily limited length of the barrel, the shortness of the time of action, and its violence, render it extremely difficult to obtain accurate and trustworthy records of pressures along the chase of a gun by direct methods; but by invoking the aid of the chemist and of the physicist in first ascertaining the properties of the explosive, that is to say, the specific volume of the gases, the quantity of heat evolved during combustion, and the specific heat of its products at high temperatures, it becomes possible to calculate curves of mean pressure which will account for the energy imparted to the projectile and to the expelled gases, although the question of abnormal local pressures, due apparently to the mode of ignition of the charge and the rate at which explosion is propagated through it, will not be revealed. This process is made the easier, in the case of smokeless explosives, because the products of combustion are wholly gaseous and retain that condition till expelled from the bore.

One of the loftiest of abstract conceptions relating to the structure of the universe, the product of many acute minds of this century, is the imagining of a substance of infinite tenuity but of immense elasticity, which permeates all space and every substance. It cannot be seen, or felt, or weighed, its composition is unknown, it cannot be pumped out of a closed vessel, it does not appear to offer any resistance to the motion of planetary bodies, and its existence is only made manifest by its property of transmitting chemical rays, light, radiant heat, electricity, and probably some more recondite forms of energy, at enormous velocity from the remotest regions of the universe and by means of vibrations the nature of which, the astounding frequency and minute pitch, have been determined by mathematicians. It is pardonable in human beings to disbelieve in 
the existence of the luminiferous ether, even though the pro. foundest thinkers and most successful workers of the present day may have all the conviction of Lord Kelvin, who has declared that " it is the only substance that we are confident of in dynamics, the one thing we are sure of is the reality and substantiality of the luminiferous ether!"

But what has the Engineer to do with such speculations, and what does it matter to him how light and heat are transmitted from the sun or from the stars, or by what mechanism heat, magnetism, and electricity are diffused over the earth? This question is being answered already in our daily practice, and is destined, no doubt, to receive fuller and more convincing response as time rolls on. I will give one or two instances. The study of the spectrum produced by the passage of light through triangular prisms has revealed the fact that the ordinary rays of white light are of a complex nature, that only a portion of them are discernible directly by the sense of sight or by that of feeling, while the ultra-violet rays can only be seen in their action on Uranium glass, or in the chemical decomposition they produce in certain substances. But, further, the spectrum viewed by modern instruments is found not to be continuous; it is crossed by dark, by light, and by coloured bands, which the patient researches of Fraunhofer, Kirchhoff, Huggins, Norman Lockyer, and others, have shown by their position, thickness, or colour to characterise certain glowing substances, and by comparison with the spectra produced by heated terrestrial solids and gases, it has been proved that many of the elements in the sun and in the stars are identical with those with which we are familiar on this earth, and this knowledge has served in a striking manner to confirm the correctness of the nebular theory as to the origin of our planetary system.

Not only have a large number of terrestrial elements been discovered in the sun, but the spectroscope has revealed, to a large extent, the order in whlch they are arranged on the sun's surface, and this leads to the conclusion that at one time a similar order prevailed on the earth, and therefore throws some light on the deep geology of our planet.

One of the practical outcomes of these discoveries has been the theory of Mendeleeff on the origin of petroleum, a theory of the utmost importance to the human race, and to our country in particular, in view of the inevitable exhaustion of our coal supplies, for it asserts that petroleum is the product of the action of water on the carbides of metals at high temperatures at no very great relative depths in the crust of the earth, that this production is continually in progress, and that deposits thus actualiy forming may be reached in many places by sufficiently deep borings; and in view of recent progress in mechanical skill, it certainly would be rash to say that borings of immensely greater depth than any that we are as yet acquainted with will never be made, for if accumulated evidence as to the correctness of Mendeleeff's views together with the ever-increasing cost of fuel, shall hold out hopes of success, enterprising men will be found ready to embark their means in undertakings, the risks of which would not seem to be more formidable than those which surrounded the laying of the first Atlantic telegraph cable, and the rewards of success in which would be incomparably greater.

The researches of Roberts-Austen, of Osmond, Le Chatelier, and others, are slowly, but it is hoped surely, establishing laws by which the relative atomic volumes of ingredients will become a guide to the nature of their mutual interaction, and it seems probable that spectrum observations which are of such value in gauging the purity of the materials dealt with, will come in aid and in support of the indications given by automatically traced curves of rates of cooling, which have given such a deep meaning to the phenomenon of recalescence, a froperty of iron and steel which for many years remained a mere laboratory curiosity.

Many bodies, including metals and their alloys, may exist in more than one form ; sulphur, for example, assumes two allotropic states, but at ordinary temperatures and in a comparatively short time the one condition passes into the other $\mathrm{Mr}$. Addenbrook has recently prepared an alloy of aluminium. and nickel, which when freshly made possesses considerable tenacity, but which, after a few hours, crumbles into powder. The researches of Osmond seem to show that pure iron also can exist in two states-one very hard, the other soft, and it is more than probable that these states merge into each other under certain conditions of heating or cooling, or under the influence of foreign substances. There can be no doubt that steel also, in course of time, undergoes molecular change at ordinary temperatures, and possibly under the influence of strains produced by internal stresses due to unequal rates of cooling. It is a common opinion, based on experience, that tool steel should not be used as freshly made, but should be kept some months, and the same precaution applies to dies used in coining and similar operations, and to armour-piercing shot, both of which, having been hardened by necessarily unequal and rapid cooling, either accommodate themselves to the stresses engendered by slow changes in the motion of the molecules, or fail spontaneously even after months of repose. Glass undergoes similar changes, and generally materials which have been severely strained either by the external application of force, or by heating, will only gradually recover their normal condition. This has been beautifully demonstrated by Prof. Hughes, with the aid of his induction balance, on specimens of the narrow steel ribbon used in the manufacture of Longridge wire guns. A number of specimens recently submitted to him showed a remarkable uniformity of structure, but when heated to only $100^{\circ}$ and examined immediately on cooling to the normal temperature, a distinct change was observable, yet after a few hours' rest the material returned to its normal state. If such changes are measurable in ribbon $\frac{1}{4}$ in. $\times \frac{1}{10}$ in. in cross section, what may not be the molecular conflict in large masses? These may be produced by alternations of stresses as well as by changes of temperature, and point to the necessity of assisting the molecules and atoms to adjust themselves, or to return to a normal condition by raising the temperature of the substance to about the point indicated by $b$ on Chernofi's scale, below which no change in the nature of crystallisation takes place, no matter how slowly the mass is allowed to cool. This principle is recognised in many ways in the arts. In drawing wire or in solid irawn metal-work, such as tubes and cartridgecases periodical annealing must be resorted to ; moreover, experience has shown that crane-chains, for example, should be annealed from time to time if they are to be used with safety; and Mr. Webb has adopted, with the best results, the plan of treating in a similar manner the moving parts of his locomotives after they have run a certain number of miles.

I feel convinced that the frequent disasters with screw propeller shafts, especially after they have been some time in use, arise from the failure to recognise the practical bearing of the tendency to molecular change under the influence of strain and temperature. A propeller shaft is subject to constant variations of stress due to the action of the cranks of the engine, to similar variations caused by the inertia of the screw, and again to a totally different set of stresses which may often be alternately tensile and compressive, due to the wear of the journals and to the working of the hull. The remedy, I feel convinced, lies in the periodical annealing of the material which must of necessity be so hardly used.

I think that it is now generally acknowledged that the lum. iniferous ether is also the medium by which electrical energy is transmitted by some kind of vibratory motion; hence the ease with which heat or mechanical work is transformed directly into electric currents in the thermopile, or in the frictional electrical machine, and the reasonableness of the great generalisa tion that we are living on a huge magnet-the poles of which are not far from coinciding with the poles of the earth.

Any one who doubts the value of abstract science should study the construction of the mariners' compass, and especially in the improved form introduced by Lord Kelvin; let him compare the blind groping after correction for the local attraction of the ship with the beautiful and simple theory which has rendered that correction not only easy but readily adapted to changes in the ship's position in the world; he will find that there is not a more striking instance of the profoundest abstract knowledge blended with the power to turn it to practical use, than in this and in so many other labours of the distinguished man whom I have named more than once, and whom this institution is proud to number among its honorary members.

I woutd now draw your attention to a startling consequence of the undulatory theory in the power which exists of exercising influence, by what is termed induction, at great distances. Animated by the conviction that electric energy was transmitted in the same manner and by means of the same all-pervading medium as radiant energy, and that the distance to which its effects would reach should be unlimited, though the apprecia. tion might be a question of the delicacy of instruments, $\mathrm{Mr}$. Preece has succeeded in sending messages by Morse signals across the Bristol Channel between Lavernock and Flatholme, 
distance of over three miles. The electro-magnetic disturbances were excited by primary alternating currents, having a frequency sufficient to generate a low musical note in a telephone, in a copper-wire I 237 yards long, erected on poles along the top of the cliff or the mainland. The radiant electro-magnetic energy was transformed into currrents again in a secondary circuit of 610 yards long, laid along the island parallel to the first and at a distance of 3.1 miles ; the messages were read off on the island through the instrumentality of the induced currents.

Any one who has meditated deeply on the nature of the luminiferous ether and on its universal presence has probably felt that it must also be $c$ ncerned in the action of the human brain. The mechanisms of the "five gateways of sense" have been worked out by anatcmists and physicists, but their researches are incompetent to declare how the impressions sent along the nerves at last reveal themselves as images or perceptions in the mind. Lord Kelvin has discoursed on this matter; he has sug. gested the existence of a magnetic sense, and has shown that the mind may be influenced independently of the recognised organs of perception. There are undoubtedly occult phenomena which can only be accounted for by the supposition that one mind can interact upon another, even as Mr. Preece's parallel wires acted on each other.

Setting aside the immense amount of calculated delusion and imperfect observations which has characterised animal magnetism, clairvoyance, \&c., though probably not more than astrology, necromancy, transmutation of metals, and other delusions, hampered the early advance of physical and chemical science, there still remains a substantial amount of authentic fact on which argument may be founded. Prof. Oliver Lodge drew attention to the matter in his Presidential Address to section A at the mee:ing of the British Association in Cardiff in 1891 , and in the opinion of that acute investigator the subject seems to deserve the attention of scientific societies.

It is less than fifty years since the nature of epidemics and the mode of their propagation seemed to be beyond the reach of human comprehension, and when Pasteur commenced his classic investigations into the causes of fermentation and of contagious disease, no one, I presume, thought that such an abstruse study as bacteriology could ever be of the least interest to engineers, nor would they have thought that the controversy relating to spontaneous generation, which raged so fiercely only a few years ago, conld have influenced the science to which they were devoted.

But the triumphan demonstrations of Pasteur, of Lister, of Burdon Saunderson, of Tyndall, and of many other workers at home and abroad have shown that there is no such thing as spontaneous generation; that zymotic diseases, those scourges of animal and vegetable life, are caused by living organisms whose modes of profragation and of travel are being eagerly studied, and are day by day being better understood; they have shown that we are nc longer fighting at random against an unknown and covert en:my, but are face to face with a subtle foe, whose tactics we are rapidly learning to understand. We have discovered that his best allies are to be found in the carelessness of his victims as to cleanliness, to drainage, and water supply, and that his most formidable enemy is the engineer, who, being guided by the sbstract investigations of the biologist and the chemist, can sele:t with certainty the most fitting source of potable water, and can get rid of the sewage of centres of population, not only without inflicting injury on the surrounding community, but very often actually benefiting them by removing existing sources of pollution and by increasing the productiveness of the soil.

But not alone in sinitary matters has bacteriology produced profitable results ; it may truly be said that the great industries of brewing, of wine and vinegar-making, and many other manufactures, have been placed on a sound footing by the knowledge we now possess of the occult action of ferments and of bacteria; and evin in agriculture the true nature of the operations which tak: place in soil, by which the nitrogenous food of plants is rencered capable of assimilation, is one of the triumphs of the research of these our days. Schloesing, Müntz, Pasteur, Munro, Percy Frankland, and others, have shown that one of the most important of plant-foods in the soil is nitric acid, and that this substance is elaborated from ammonia by the action of minute living organisms. The singular fact has been demonstrated that the work is performed by a system of division of labour, one kind of bacterium converting the ammonia into nitrous acid and declining to do any more, when another species takes up the work and produces nitric acid, which presents the nitrogen in a form which can be assimilated by the plant. "Not only," to use the words of Dr. P. Frankland, "is this process of nitrification going on in the fertile soils, but enormous accumulations of the products of the activity of these minute organisms in the shape of nitrate of soda are found in the rainless districts of Chili and Peru, from whence the Chili saltpetre, as it is called, is exported in vast quantities, more especially to fertilise the overtaxed soils of Europe!" But more than that, long and patient research has established the fact that, in certain of the legumenous plants, the same microscopic agency acting in the roots endows them with the power of assimilating the nitrogen of the atmosphere, and by that means makes them the instruments for actually enriching the soil instead of exhausting it.

I have already alluded to the circumstance that the engineer cannot be satisfied with vague statements or with mere abstract opinions. The very nature of his calling implies action; he has to construct, his works must be stable, his machinery must act, his estimates of cost and of the consequences of his operations must come true, and hence he has to make a close alliance with that most fascinating and fruitful of the sciences-mathematics. It is not given to many to possess the peculiar aptitude which leads up to the highest investigation, but neither has the engineer often need of anything deeper than almost elementary knowledge, especially if he gets into the habit of working out the problems that come before him by the graphic methods which are now so assiduously cultivated, and if he will realise that slovenliness in the matter of calculations commonly leads to disastrous results. Though his attainments may not be high, and though disuse may have made it difficult to wield the power which knowledge, early acquired, once gave him, yet he can always appreciate and put his faith in the great minds which delight in subjecting the theories of physicists to the rigid test of mathematical analysis, and thereby stamping them with the seal of irrefragable fact.

One great quality he must possess, especially in these days when numerous science colleges have rendered high mathematical training of easy access-and that is common sense. There is a tendency among the young and inexperienced to put blind faith in formulæ, forgetting that most of them are based upon premises which are not accurately reproduced in practice, and which, in any case, are frequently unable to take into account collateral disturbances, which only observation and experience can foresee, and common sense provide against.

I have endeavoured to show how the history of abstract science, by which I intend to designate the history of researches entered into for the sole purpose of acquiring knowledge of the operations of Nature and of her laws, without any thought of reward, or expectation of pecuniary advantage, has had its reflex in the records of the engineering profession, and how the most recondite investigations, apparently unlikely to have any direct influence on our practice, have, in course of time, become of cardinal importance. I have also ventured to point out how, in these days, the engineer must banish from his mind the idea that anything can be too small or too trifling to deserve his attention. "Nothing is too small for the great man," is, I am told, written over the cottage once occupied by Peter the Great at Saardam. The truth embodied in that legend should ever dwell in our minds; for succesș, I am persuaded, lies largely in close attention to details.

The discourse concluded by a warm tribute to the merits of the old servant of the Institute who had established the lectureship.

\section{UNIVERSITY AND EDUCATIONAL INTELLIGENCE.}

CAMBRIDGE.-It is proposed to appoint a Syndicate for the purpose of considering the desirability of establishing an examination in agricultural science, open to all trained students, whether members of the University or not. The successful candidates in such an examination would receive a University diploma similar to the existing diploma in Public Health. It is understood that this plan has received the approval of the Royal Agricultural Society and the Board of Agriculture. These bodies, and certain of the County Councils, have further agreed to subsidise a scheme for the regular instruction within the University of candidates for the examination if it be established. NO. I 229 , VOL. 48 ] 